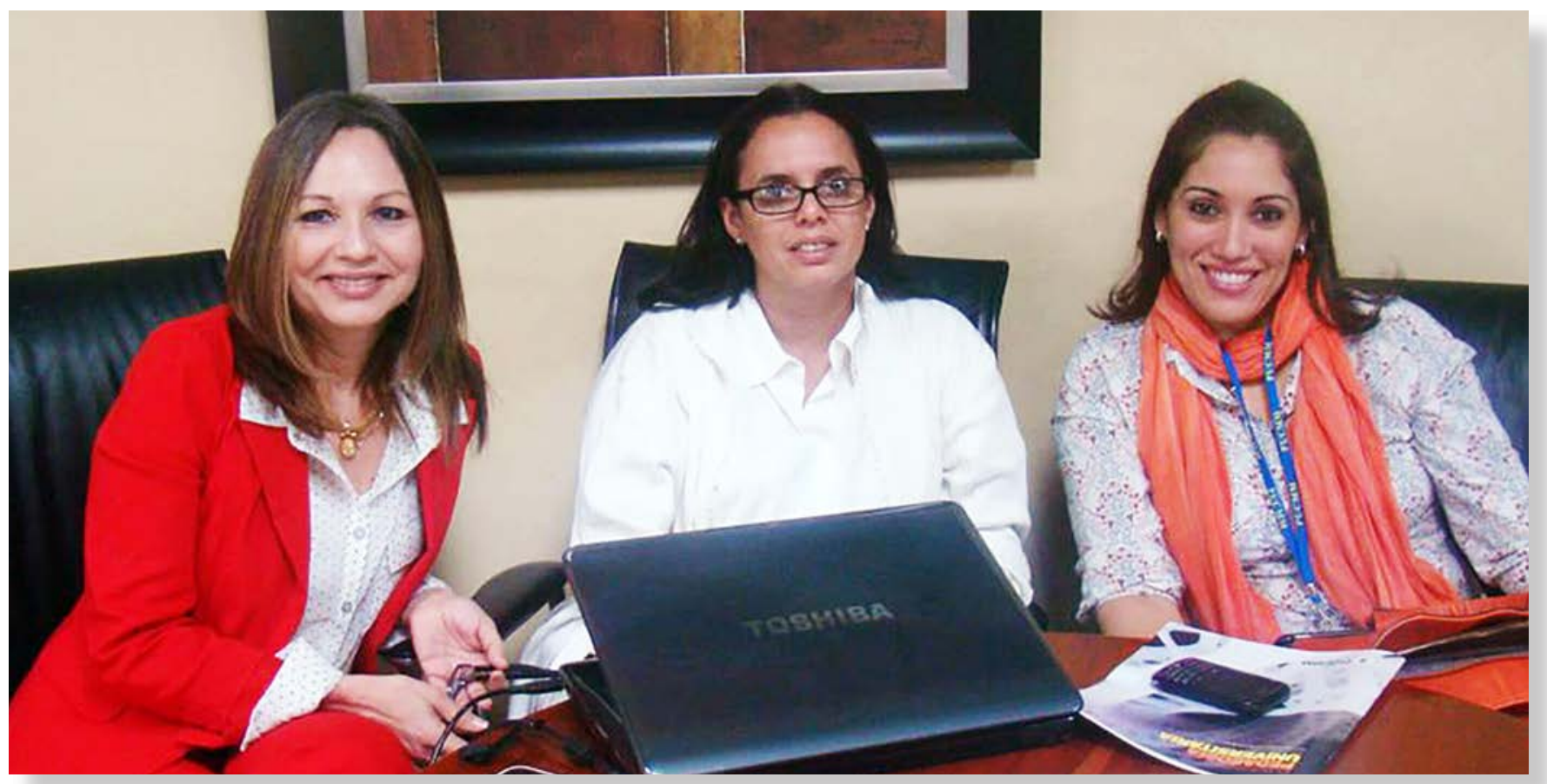

\title{
La XII peña pedagógica
}

Estos encuentros, de carácter informal entre el profesorado de la PUCMM, se organizan dos veces al año, para compartir ideas y opiniones de los artículos publicados en la edición más reciente del Cuaderno de Pedagogía Universitaria.

La reunión se llevó a cabo el 20 de noviembre de 2013, en el campus de Santiago. A continuación reseñamos las ideas principales.

cos articulistas de la edición anterior, Máximo Pérez, escritor del artículo Creatividad en la docencia universitaria; Marta Vicente, Manejo didáctico de la imagen; Mayra Ruiz, Coaching para mejorar el proceso de enseñanzaaprendizaje y Rebeca Espinosa, reseña del libro Evaluación de habilidades y competencias en educación superior, estuvieron presentes en La peña exponiendo y discutiendo el contenido de sus artículos mediante un diálogo abierto al intercambio de ideas.

La peña inició con la ponencia de Pérez sobre su experiencia en el proceso de investigación para la realización del artículo, cómo se apasionó por el tema y tuvo que deliberar para poder enfocarse en lo que era realmente elocuente para la ocasión. Expresó que fue un reto para él poder hilar y dar sentido a las diferentes ideas expuestas. Se habló de la relevancia, el auge del tópico a nivel internacional y cómo en el contexto dominicano no se han aprovechado al máximo sus beneficios. Como resultado de su presentación llegó a la conclusión de que si se pretende innovar en los contextos pedagógicos se tiene que implementar la creatividad.

El profesor José Reynoso aprovechó la ocasión para cuestionar al autor sobre cómo puede influenciar el docente en el desarrollo de la creatividad en el estudiantado. Pérez sostuvo que este proceso implica una diversidad de temas que atañen el acercamiento a diferentes culturas, así como el contacto con diferentes puntos de vista, esto por parte del estudiantado; explicó que en el caso de los docentes es necesario propiciar que el estudiante construya su propio conocimiento mediante la asignación de proyectos, realización de preguntas abiertas, resaltando la importancia de la originalidad y adaptación de los programas de las asignaturas a las necesidades de los grupos a los que se orientan. 


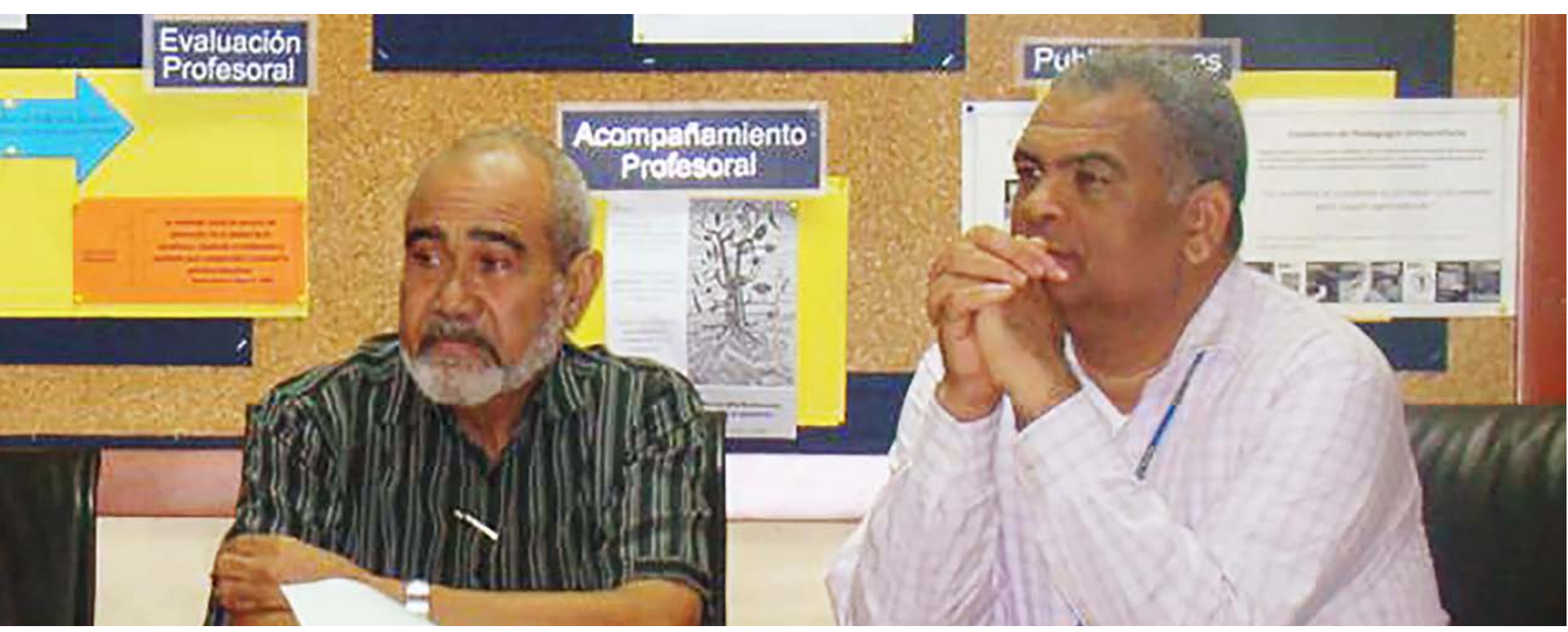

En este sentido, Ivette Ramírez reconoció lo enunciado por Pérez, destacando que es imposible desarrollar dicha competencia en el estudiantado sin que primero haya sido fomentada en el docente. Afirma que todo lo que le permita al docente realizar diversos cambios es creatividad y que es un compromiso del maestro que no sólo implica la voluntad de cambiar sino la capacidad de indagar nuevos métodos evaluativos y didácticos.

La Decana de Ciencias de la Salud, Mariana Moreno, aprovechó la oportunidad para resaltar que es un desafío para los docentes mantenerse a la vanguardia en su área de ejercicio laboral, así como en el uso de los recursos tecnológicos para el buen desempeño en la enseñanza de esta competencia.

Ariosto Díaz reconoció la importancia de cultivar la creatividad en el día a día del quehacer docente. Señaló la trascendencia de la integración del profesorado a las actividades que ofrece el Centro de Desarrollo Profesoral (CDP), quienes a menudo habilitan cursos y talleres, que son las herramientas claves y que asisten en la mejora constante del quehacer docente.

La profesora Sandra Hernández compartió que cuando quiere desarrollar destrezas de pensamiento creativo lo logra a través de la investigación. El profesor Reynoso resaltó que la creatividad se desarrolla a partir de la convicción, actitud y disponibilidad del receptor para llevarla a cabo. Mayra aprovechó para estimular a los colegas presentes a hacer uso de los beneficios del CDP e instó a los profesores a que compartan con el Centro ideas que surjan a partir de sus prácticas docentes.
Otro artículo discutido durante la Peña fue el Manejo didáctico de la imagen, de la autoría de Marta Vicente, quien refirió que el objetivo principal del artículo fue compartir las notas del taller sobre dicha temática. En la primera parte están los objetivos o competencias e intenciones educativas. Lo demás está vinculado a los contenidos, estrategias, recursos, evaluación y la intención pedagógica.

En la discusión de ideas los presentes llegaron a la conclusión de que los docentes no han explotado al máximo el recurso visual. La imagen es esencial, pero es crucial saber utilizarla con propiedad.

La Dra. Moreno sugiere al CDP el desarrollo de una investigación sobre las ventajas del uso de la imagen en clases de patología y biología, de manera que se pueda medir la repercusión de la estimulación visual en el aprendizaje y resaltó la importancia de la imagen aún en materias que son más teóricas, como la filosofía.

La profesora Yngris Balbuena hizo la salvedad de que las imágenes pueden captar la atención de los alumnos, pero no satisfacen su objetivo si carecen de sentido e intencionalidad de lo que se pretende comunicar. La intencionalidad de la imagen debe ser que el receptor reciba estimulación que lo conduzca a interpretar e incitar el pensamiento. En este sentido, se resaltó la importancia del uso de imágenes, comerciales y corto metrajes contextualizados con los tópicos a lugar e integrarlos a la docencia, esto también como una forma de innovar y promover la creatividad.

La articulista, Mayra Ruiz, disertó acerca de su exposición sobre coaching. "El coaching es un reto para 
lograr lo que te propones". Es un método, que desde el punto de vista educativo, ayuda al proceso de enseñanza, potencia el aprendizaje y logra el rendimiento esperado. Su estructura se basa en preguntas y se vincula a lo discutido anteriormente, en el fomento de la creatividad, puesto que se basa en preguntas abiertas que responden a cómo y para qué. El coaching se basa en las competencias del profesor. Se trata, por ejemplo, de cambiar el mensaje de estás cansado, al de qué te pasa; pues de esta manera, más que enseñarlos, los acompañamos en el proceso de aprendizaje. Rebeca aportó que el coaching te lleva a reflexionar acerca de cuáles son tus prioridades, qué quieres trasmitir, a dónde quieres llegar y cómo puedes lograrlo.

Finalmente se socializó la reseña del libro "Evaluación de habilidades y competencias en educación superior". Se hizo hincapié en las necesidades educativas para estudiantes con necesidades especiales, manifestando que la Universidad debe continuar preparándose para dar respuestas a las requisiciones de dichos alumnos; tanto en la infraestructura física, como en los procesos de evaluación. Ambos con el cometido de que el proceso pedagógico sea viable y alcanzable. Además, se reflexionó acerca del reto de formar estudiantes con condiciones físicas y psicológicas especiales y se recomendó la creación de un comité conformado por miembros de los Departamentos de Orientación, Ciencias de la Salud, el Decanato de Estudiantes, entre otros, con la finalidad de elaborar políticas y protocolos para el seguimiento de estos casos.

Como cierre del encuentro la licenciada Rafaela Carrasco, Directora del Centro de Desarrollo Profesoral (CSTI), agradeció a los presentes por sus aportes y dirigió unas palabras de reconocimiento a la licenciada Marta Vicente por su eficiente trabajo durante el período de tiempo que ejerció como Directora Ejecutiva del Cuaderno de Pedagogía Universitaria.

Asistentes a la Peña: Juan Zapata, Leonardo Belliard, Ivette Ramírez, Idelise Sagredo, Marta Vicente, Rafaela Carrasco, Máximo Pérez, Mayra Ruiz, José Reynoso, Ariosto Díaz, Mariana Moreno, Rebeca Espinosa, Nora Ramírez, Sandra Hernández e Yngris Balbuena.
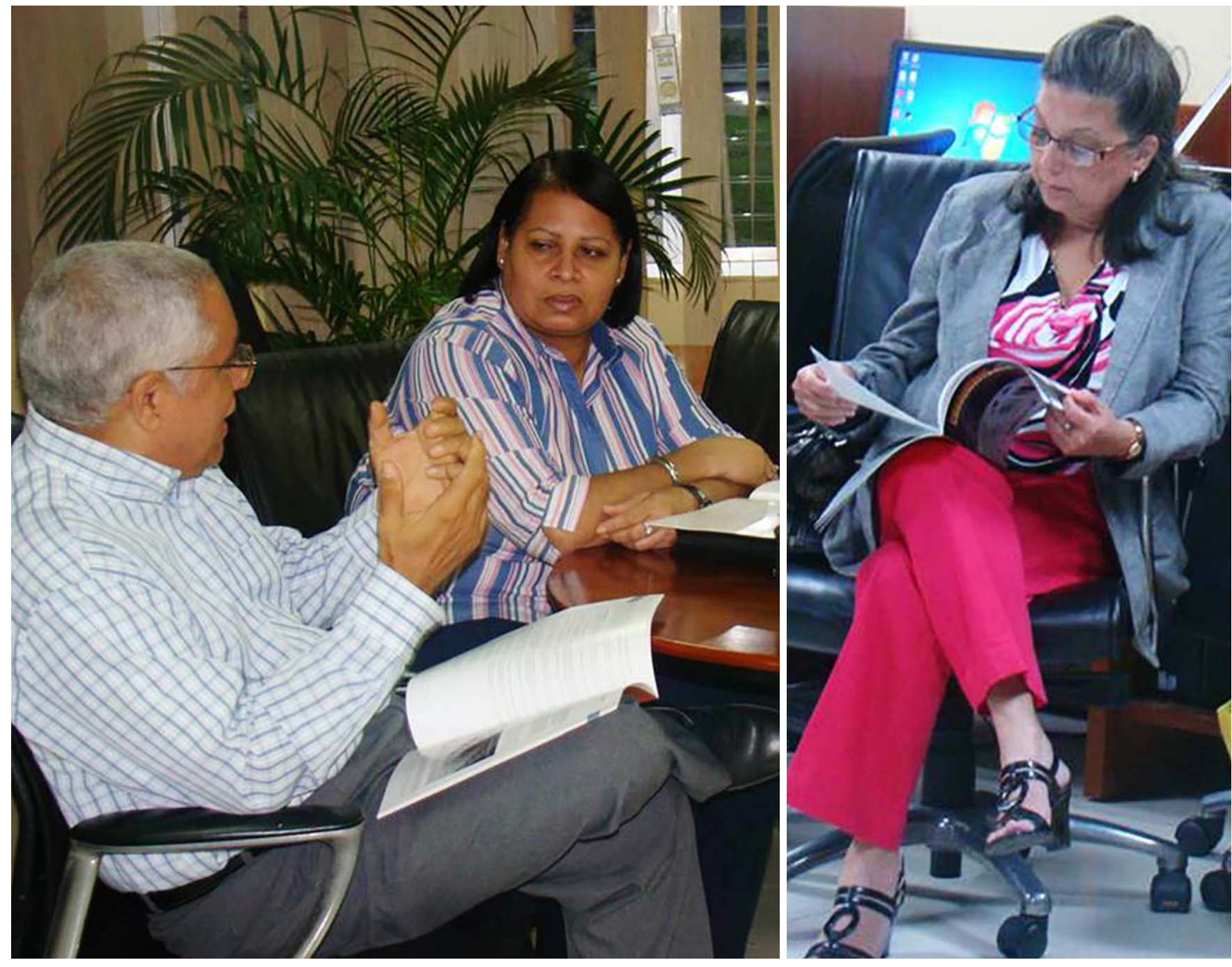